\title{
Coulisses
}

Revue de théâtre

25 | Hiver 2002

Varia

\section{Un programme consolidé}

Calendrier d'activités 2001-2002

\section{(2) OpenEdition}

\section{Journals}

Édition électronique

URL : http://journals.openedition.org/coulisses/6101

DOI : 10.4000/coulisses.6101

ISSN : 2546-9460

\section{Éditeur}

Presses universitaires de Franche-Comté

\section{Édition imprimée}

Date de publication : 1 janvier 2002

Pagination : 119-120

ISBN : 2-84627-052-X

ISSN : $1150-594 \mathrm{X}$

\section{Référence électronique}

« Un programme consolidé », Coulisses [En ligne], 25 | Hiver 2002, mis en ligne le 24 octobre 2019,

consulté le 15 novembre 2019. URL : http://journals.openedition.org/coulisses/6101 ; DOI : 10.4000/ coulisses.6101

Ce document a été généré automatiquement le 15 novembre 2019.

Coulisses 


\section{Un programme consolidé}

Calendrier d'activités 2001-2002

\section{SEPT-OCT : Participation aux réunions d'information}

- 29 sept : Participation à la journée de l'Anrat

\section{OCTOBRE : Rentrée du T.U.F.C, reprise des ateliers}

- 15 Oct : Inauguration de la semaine de « La science en fête » (15-21 oct.) en partenariat avec l'Université Ouverte et le Projet Aurore.

- Présentation des Cahiers de Coulisses $n^{\circ} 2$ : Incertitudes de la mécanique quantique devenant chant des oiseaux du Graal pour l'entrée des groupes (de Galois) dans le langage dramatique, Pièce d'Armand Gatti.

- Présentation des Actes du colloque Temps scientifique, temps théâtral édité par le CRDP et qui a obtenu le label de la Mission Art et Culture.

- Un dialogue entre Francis Bailly (chercheur en physique du solide au C.N.R.S.) et Armand Gatti, auteur : Croisement des langages sciences et poésie.

- Une animation théâtrale, le mercredi 17 , de $14 \mathrm{~h}$ à $16 \mathrm{~h}$, place Saint-Pierre. Mise en scène « clownesque » de textes sur la science.

- 17 oct : Réunion d'information, 20h, Amphi Donzelot

- 18 oct : Réunion d'information, 20, Salle Jenny d'Héricourt, campus de La Bouloie.

- 20-21 oct : «Coulisses » et Les Salons

- Salon de la revue avec le partenariat du C.R.L

- Marché de l'édition théâtrale (de l'Odéon). Présentation des Incertitudes de la mécanique quantique devenant chant des oiseaux du Graal pour l'entrée des groupes (de Galois) dans le langage dramatique, avec la participation de J.J. Hocquart, administrateur de la Parole errante. À cette occasion, lecture d'extraits par la Compagnie Sciences 89.

- Semaine du 22 - 28 oct. : REPRISE des ateliers du T.U.F.C.

À Besançon :

- Trois ateliers de pratique théâtrale, sous la direction de Joseph Melcore

- Atelier de « Médiation culturelle », sous la responsabilité de Lucile Garbagnati.

À Montbéliard : 
Un atelier hebdomadaire d'expression, sous la responsabilité de Francine Gaonach et Mélanie Manuelian

- 23 oct : Accueil d'un groupe d'étudiants de Zagreb, de «L'Association d'étudiants croates francophiles ", de l'université de Zagreb, en partenariat avec la mairie de Besançon.

- 24 oct : Accueil du spectacle des étudiants croates, une adaptation des Bonnes de Jean GENET. Écrit, mis en scène et interprété par Blanka Bukas, membre de l'AECF, à $19 \mathrm{~h} 30$ au Grand salon de la faculté des lettres.

- 25 oct : Participation à la journée « Les Arts de la scène à l'université ». Communication de Lucile Garbagnati sur les activités du T.U.F.C

\section{NOVEMBRE : Cycle « Rendez-vous avec le théâtre » en partenariat avec l'Université Ouverte}

- 12 nov : Intervention théâtrale à la SOIREE d'ACCUEIL des étudiants étrangers organisé par le service des relations internationales, au Kursaal à $20 \mathrm{~h}$.

- 15-16-17 nov : Colloque Théâtre et nouvelles technologies en partenariat avec le centre de recherches Jacques-Petit.

\section{DÉCEMBRE}

- 7 déc : Conseil d'administration du T.U.F.C.

- 8-9 déc: Coulisses au SALON FRANC-COMTOIS DU LIVRE, Maison de la Franche-Comté à Paris, en partenariat avec le C.R.L.

\section{JANVIER}

- du 19 au 27 janv. : Diffusion de R.A.S., création collective du T.U.F.C, à Zagreb (Croatie). Festival organisé à l'université de Zagreb.

- Coulisses $\mathbf{n}^{\circ} 25$

- Déplacement du groupe de l'atelier Approfondissement à Zagreb en Croatie.

\section{FÉVRIER}

- 1er fév.: Assemblée générale du T.U.F.C., suivie de la Fête du TU. Présentation de Coulisses $n^{\circ} 25$

Salle Jenny d'Héricourt, puis salle Cournot (ex G5), campus de la Bouloie.

\section{MARS}

- 3 : Diffusion de R.A.S à Sornais (Haute-Saône)

- 9 : Diffusion de R.A.S à Besançon, Petit Théâtre de la Bouloie.

- du 11 au $15: 1^{\mathrm{e}}$ RITUFC à Besançon. Le 14, délocalisation à Lons-le-Saunier, en partenariat avec le Théâtre municipal et l'IUFM

- le 21 Conférence-lecture de G. Danou, Henri Michaux, poétique du langage médical, dans le cadre de « Science en culture » en partenariat avec le Projet Aurore.

- le 29 : Participation à Univerl'Art : journée des associations culturelles de l'université de Franche-Comté 
- le 29 : Diffusion de R.A.S à Dijon, lors d'un festival universitaire.

- le 30 : Diffusion de R.A.S à Lyon, lors du festival de l'E.N.T.P.E

\section{MAI}

- 13, 17h : Conférence de Lucile Garbagnati « le Théâtre universitaire dans la Cité », dans le cadre du PPF « Ville Cité Territoire », organisée par le centre Jacques-Petit.

- Lecture des nouvelles lauréates du Grand Prix de la nouvelle du CROUS.

- Coulisses $n^{\circ} 26$

- 18 : Diffusion de R.A.S à Dunkerque, lors d'un festival

\section{JUIN}

- Création du T.U.F.C.

- Publication des Actes du colloque Théâtre et nouvelles technologies.

\section{JUIN, JUILLET, AOUT 2002}

- Résidence - création avec Armand Gatti et une trentaine d'étudiants français et francophones au campus de La Bouloie. Co-organisé avec la Parole errante. 